Received: 19 October 2017

Accepted: 25 January 2018

Published online: 12 February 2018

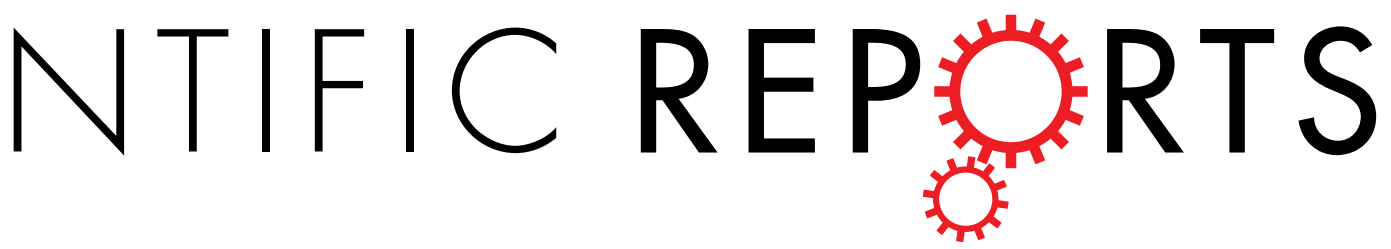

\title{
OPEN The wavelength of the incident light determines the primary charge separation pathway in Photosystem II
}

Andrea Pavlou, Julien Jacques, Nigar Ahmadova, Fikret Mamedov (i) \& Stenbjörn Styring

Charge separation is a key component of the reactions cascade of photosynthesis, by which solar energy is converted to chemical energy. From this photochemical reaction, two radicals of opposite charge are formed, a highly reducing anion and a highly oxidising cation. We have previously proposed that the cation after far-red light excitation is located on a component different from $\mathrm{P}_{\mathrm{D} 1}$, which is the location of the primary electron hole after visible light excitation. Here, we attempt to provide further insight into the location of the primary charge separation upon far-red light excitation of PS II, using the EPR signal of the spin polarized ${ }^{3} \mathrm{P}_{680}$ as a probe. We demonstrate that, under far-red light illumination, the spin polarized ${ }^{3} \mathrm{P}_{680}$ is not formed, despite the primary charge separation still occurring at these conditions. We propose that this is because under far-red light excitation, the primary electron hole is localized on $\mathrm{Chl}_{\mathrm{D} 1}$, rather than on $\mathrm{P}_{\mathrm{D} 1}$. The fact that identical samples have demonstrated charge separation upon both far-red and visible light excitation supports our hypothesis that two pathways for primary charge separation exist in parallel in PS II reaction centres. These pathways are excited and activated dependent of the wavelength applied.

Several billion years ago, the evolution of photosynthetic organisms capable of splitting water into molecular oxygen $\left(\mathrm{O}_{2}\right)$, protons $\left[\mathrm{H}^{+}\right]$, and electrons $\left(e^{-}\right)$with the mere absorption of sunlight, completely altered the course of evolution of life ${ }^{1,2}$. The complex photosynthetic reactions in these organisms (plants, algae and cyanobacteria), allow them to take in carbon dioxide $\left(\mathrm{CO}_{2}\right)$, water and light energy to produce carbohydrates and $\mathrm{O}_{2}$, vital products for life sustainment. These light-dependent reactions take place in two multi-protein membrane complexes known as Photosystem II (PS II) $)^{3}$ and Photosystem I (PS I) ${ }^{4}$. PSII absorbs photons to use their energy to oxidize water, thereby supplying PS I with electrons to be used in carbon fixation ${ }^{5,6}$.

In PS II, absorption of a photon first results in excitation of photosynthetic pigments and very rapidly thereafter in the primary charge separation reaction between the primary donor of PS II, commonly referred to as $\mathrm{P}_{680}$, and the first electron acceptor, pheophytin (Pheo). In a series of subsequent electron transfer reactions, electrons are transferred from water (that is split into $\mathrm{O}_{2}$ when oxidized) to the first and second quinone electron acceptors, $\mathrm{Q}_{\mathrm{A}}$ and $\mathrm{Q}_{\mathrm{B}}{ }^{7,8}$. Unlike anoxygenic phototrophic bacteria, which contain bacteriochlorophylls that can drive anoxygenic photosynthesis at wavelengths longer than $900 \mathrm{~nm}$, oxygenic photosynthesis was thought to be limited to wavelengths below ca $690 \mathrm{~nm}$, also known as the red drop phenomenon as defined by ${ }^{9}$. The reason behind this difference was attributed to the high energy required for water oxidation in oxygenic photosynthesis, where $\mathrm{O}_{2}$ is released as a by-product. Lower energy photons above $c a 690 \mathrm{~nm}$ were assumed to be unable to generate a redox potential that is high enough to drive water oxidation, while concomitantly retaining a negative excited state redox potential on the acceptor side required for the reduction of the primary electron acceptor ${ }^{10}$.

The notion that oxygenic photosynthesis can only be driven by photons with a maximum absorbance at or below $\sim 690 \mathrm{~nm}$ involving Chl $a$, drastically changed with the discovery of the cyanobacterium Acaryochloris marina $^{11-13}$. This photosynthetic cyanobacterium has $\sim 95 \%$ of its $\mathrm{Chl} a$ substituted by Chl $d$, which is red-shifted with an absorbance maximum of $\sim 710 \mathrm{~nm}$. Despite this, $A$. marina is still able to oxidize water ${ }^{14,15}$. This results in efficient photochemistry taking place in a submarine ecosystem deficient in visible light, but largely penetrated by far-red light ${ }^{16-18}$. Thus, it is clear that photosynthetic water oxidation in nature can occur also with photons of 


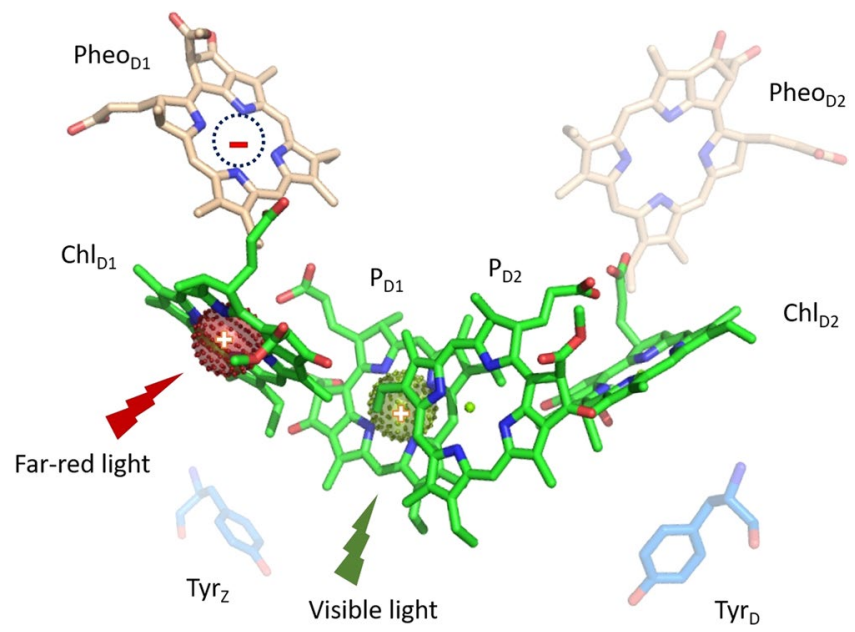

Figure 1. Structural representation of the redox active components in the PS II reaction center.

energy lower than $690 \mathrm{~nm}$. Interestingly, this also holds for PS II in green algae ${ }^{19}$ and higher plants ${ }^{20,21}$ containing a Chl $a / b$ antennae without any $\mathrm{Chl} d$. Spectroscopic investigation of the different electron transfer reactions in PS II, defined the far-red limit for water-oxidizing photochemistry in PS II to $780 \mathrm{~nm}$ (single flash) up to $800 \mathrm{~nm}$ (photoaccumulation) $^{22}$. Based on these findings, an alternative charge separation pathway was proposed to occur upon far-red light excitation. When this pathway is activated, a state denoted $\mathrm{X}^{*}$ that is lower in energy compared to $\mathrm{P}_{680} *$ (formed in visible light) is formed in PS II. Despite its lower energy, $\mathrm{X}^{*}$ is able to trigger the charge separation, reduce $\mathrm{Pheo}$ and oxidize tyrosine $\mathrm{Z}\left(\mathrm{Y}_{\mathrm{Z}}\right)$.

This is an important evolutionary finding as it has redefined the required threshold energy for oxygenic photosynthesis, since $\mathrm{X}^{*}$ apparently works with an energetic threshold which is lower than $\mathrm{P}_{680} * 22$. The existence of such a state was suggested previously, but never shown to induce charge separation at room temperature or at wavelengths as high as $800 \mathrm{~nm}$. Although oxygen evolution and variable chl $a$ fluorescence have been observed in sunflower (Helianthus annuus) and bean (Phaseolus vulgaris) leaves using wavelengths up to $780 \mathrm{~nm}^{21}$, the maximum long wavelength with which successful charge separation was achieved was $730 \mathrm{~nm}$, as demonstrated by spectral hole-burning experiments on PS II core complexes at cryogenic temperatures $(1.5 \mathrm{~K})^{23,24}$. This range has now been extended to $\mathrm{ca} 780-800 \mathrm{~nm}$ where complete water oxidation can be achieved at room temperature in different PS II preparations ${ }^{22}$.

Mokvist et al., 2014 provided further insight into the electron transfer reactions in PS II, induced by far-red photochemistry ${ }^{25}$. It was shown that at $5 \mathrm{~K}, \mathrm{Y}_{\mathrm{Z}}$ was the preferred secondary electron donor in far-red light. This is different from the situation with visible light where the Cyt $b_{559} / \mathrm{Chl}_{\mathrm{Z}} / \mathrm{Car}_{\mathrm{D} 2}$ secondary pathway was equally important $\mathrm{t}^{25}$.

This observation led to the proposal of a different first stable charge pair denoted as $\mathrm{P}_{\mathrm{x}}{ }^{+} \mathrm{Q}_{\mathrm{A}}{ }^{-}$being formed under far-red light, as compared to the normal $\mathrm{P}_{\mathrm{D} 1}{ }^{+} \mathrm{Q}_{\mathrm{A}}{ }^{-}$under visible light excitation. The proposed electron hole in $\mathrm{P}_{\mathrm{x}}{ }^{+}$was suggested to be residing on the $\mathrm{Chl}_{\mathrm{D} 1}$ molecule in the PS II reaction centre at $5 \mathrm{~K}$. The observation also further supported the proposed existence of a low-energy threshold charge separation pathway, where the primary donor is $\mathrm{Chl}_{\mathrm{D} 1}$ rather than $\mathrm{P}_{\mathrm{D} 1}{ }^{25}$. (See Fig. 1 which shows the redox active components in the PS II reaction centre from ref. ${ }^{26}$ ).

In this study, we have used the spin polarized triplet EPR signal from ${ }^{3} \mathrm{P}_{680}$, to further probe the photochemistry following visible or far-red illumination. Our results strengthen the hypothesis that the stable cation formed by the charge separation resides at $\mathrm{Chl}_{\mathrm{D} 1}$ when the excitation energy is provided by long wavelength (far-red) light, rather than on $\mathrm{P}_{\mathrm{D} 1}$ of the $\mathrm{P}_{\mathrm{D} 1} / \mathrm{P}_{\mathrm{D} 2}$ Chl pair, which is the normal situation in visible light excitation.

\section{Results}

Functionality of over-reduced PS II. The experimental protocol to achieve reliable and quantitative double reduction of $\mathrm{Q}_{\mathrm{A}}$ in PS II enriched membranes of our type (so called BBY particles), is complicated and has several potential pitfalls. The double reduction protocol involves reduction with sodium dithionite using benzyl viologen as mediator for several hours and demands exclusive handling under anaerobic and dark conditions ${ }^{27-29}$. Also the re-oxidation protocol is difficult and could potentially lead to sample damage ${ }^{27}$. It was therefore important to test for the integrity of the critical electron transfer reactions both after double reduction and after the re-oxidation of the samples used here.

Status of the charge separation reaction. The most important reaction in the current study is the primary charge separation reaction. In PS II centres with $\mathrm{Q}_{\mathrm{A}} \mathrm{H}_{2}$ (double reduced and protonated $\mathrm{Q}_{\mathrm{A}}$ ) or samples lacking $\mathrm{Q}_{\mathrm{A}}$, the primary charge separation can be followed by photo-accumulation of the $\mathrm{Pheo}^{-}$radical under reducing conditions $^{30-32}$. This reaction is also known to be functional using far-red illumination ${ }^{22}$.

Figure 2 shows the EPR signal from the Pheo- radical in PS II enriched membranes where $\mathrm{Q}_{\mathrm{A}}$ was doubly reduced. The radical EPR spectrum formed by either visible or far-red $(732 \mathrm{~nm})$ light was $13 \mathrm{G}$ wide with $g=2.0035^{30-32}$. Both parameters are indicative that the signal originates from the $\mathrm{Pheo}^{-}$radical. Thus, the mere 


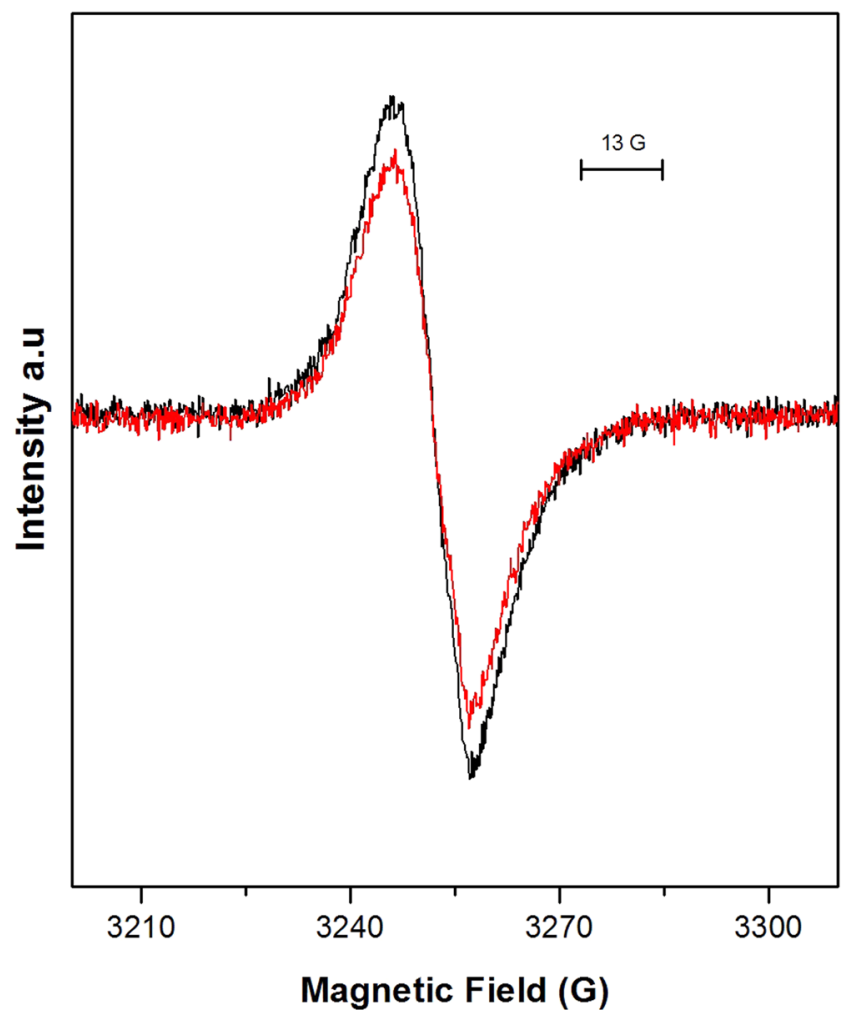

Figure 2. EPR signal of the $\mathrm{Pheo}^{-}$radical in doubly reduced PS II membranes, after continuous illumination with white (black) and far-red at $732 \mathrm{~nm}$ light (red), at $20^{\circ} \mathrm{C}$, for 6 and $10 \mathrm{~min}$ respectively. EPR conditions were as follows: microwave power $1.27 \mu \mathrm{W}$, microwave frequency $9.139 \mathrm{GHz}$, modulation amplitude $3.5 \mathrm{G}$, temperature, $15 \mathrm{~K}$.

formation of the signal is an indication that PS II was able to perform the charge separation reaction despite being exposed to the dithionite/benzyl viologen reduction protocol. The size of the EPR spectrum from Pheo $^{-}$ can be compared to the size of the EPR spectrum from the $\mathrm{Y}_{\mathrm{D}} \cdot$ radical in the corresponding intact PSII sample (non-reduced) that amounts to $1 \mathrm{radical} / \mathrm{PSII}$ reaction center ${ }^{33,34}$. In this particular experiment, exposure to white light resulted in $\mathrm{Pheo}^{-}$radical formation in $70 \%$ of PS II, while the illumination at $732 \mathrm{~nm}$ resulted in $\mathrm{Pheo}^{-}$radical formation in $55 \%$ of PS II. We can thus conclude that $\geq 70 \%$ of the PS II centres can perform the primary charge separation after the reduction treatment. In addition, it seems that $732 \mathrm{~nm}$ is nearly as efficient as white light, the small difference probably reflecting the weaker light source used at $732 \mathrm{~nm}$.

Status of the Mn-cluster. It is generally thought that extensive reduction of PS II results in inactivation of the OEC through removal of the $\mathrm{CaMn}_{4}$-cluster. This also holds for our samples that showed typical characteristics of samples lacking the $\mathrm{CaMn}_{4}$-cluster. After the re-oxidation procedure, no $\mathrm{O}_{2}$ evolution could be detected. Corroborating this, neither the Split $S_{1}$ EPR signal nor the $S_{2}$ state multiline EPR signal, both involving a functional $\mathrm{CaMn}_{4}$-cluster, could be detected (EPR spectra not shown).

Status of Tyrosine-D oxidation and the quinone acceptors $Q_{A}$ and $Q_{B}$. Chemical double reduction of $Q_{A}$ is most probably followed by protonation, forming $\mathrm{Q}_{A} \mathrm{H}_{2}{ }^{27-29}$. Presumably this species could leave the $\mathrm{Q}_{\mathrm{A}}$-binding pocket irreversibly during the very long double reduction procedure. However, this does not seem to be the case, at least not in the majority of the PSII centres. In the re-oxidized samples, $\mathrm{Y}_{\mathrm{D}}{ }^{\bullet}$ could be formed in a major fraction of the PS II centres $(>55 \%)$ (Fig. 3, red trace). $\mathrm{Y}_{\mathrm{D}}$ oxidation involves both primary photochemistry in PSII (charge separation between $\mathrm{P}_{680}$ and Pheophytin) and the transfer of, at least, one electron to the quinones on the acceptor side of PS II. Thus the formation of $\mathrm{Y}_{\mathrm{D}}{ }^{\bullet}$ unequivocally shows both that charge separation worked (Figs 2 and 3, red trace) and that $\mathrm{Q}_{\mathrm{A}}$ remained bound in a majority of the samples despite the harsh double reduction/re-oxidation protocols.

We also performed flash induced fluorescence measurements in the re-oxidized samples. Our results show that a large fraction of PSII was able also to perform secondary electron transfer. After the flash, the immediate fluorescence induction is indicative of reduction of $\mathrm{Q}_{\mathrm{A}}$, when bound to its binding pocket. $\mathrm{Q}_{\mathrm{A}}{ }^{-}$then decays with different kinetics dependent on the integrity of PSII. The dominating intermediate decay phase in our samples (calculated half-life $=13 \mathrm{~ms}$ ) (Fig. 4, black trace), is similar to the $\mathrm{Y}_{\mathrm{Z}}{ }^{\bullet} \mathrm{Q}_{\mathrm{A}}{ }^{-}$recombination phase observed in for example Tris-washed PS II membranes ${ }^{35}$. In Tris-washed PSII membranes the OEC is absent, corroborating our conclusion that our samples after double reduction and re-oxidation had lost the $\mathrm{CaMn}_{4}$-cluster. 


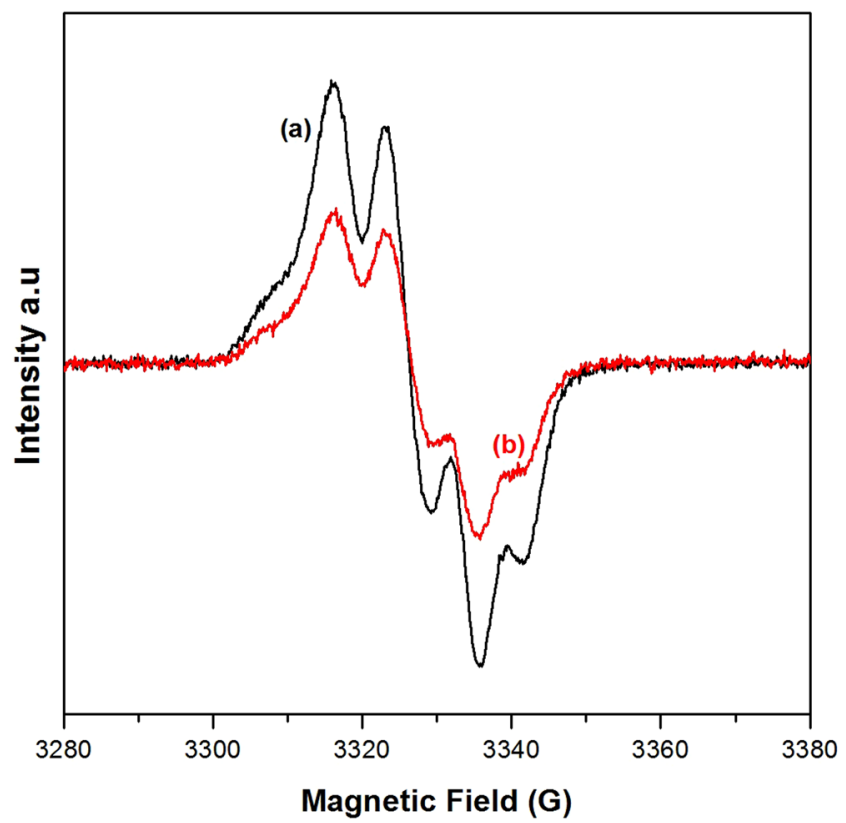

Figure 3. (a) The radical EPR spectrum of maximum oxidized $Y_{D}$ (black) as measured from an untreated PS II sample. (b) The radical EPR spectrum of oxidized $\mathrm{Y}_{\mathrm{D}}$ (red) as measured from a similarly concentrated PSII sample where $\mathrm{Q}_{\mathrm{A}}$ was re-oxidized after double reduction with sodium dithionite/benzyl viologen (see Materials section). EPR conditions: microwave power $1.3 \mu \mathrm{W}$, microwave frequency $9.28 \mathrm{GHz}$, modulation amplitude $3.5 \mathrm{G}$, temperature $15 \mathrm{~K}$.

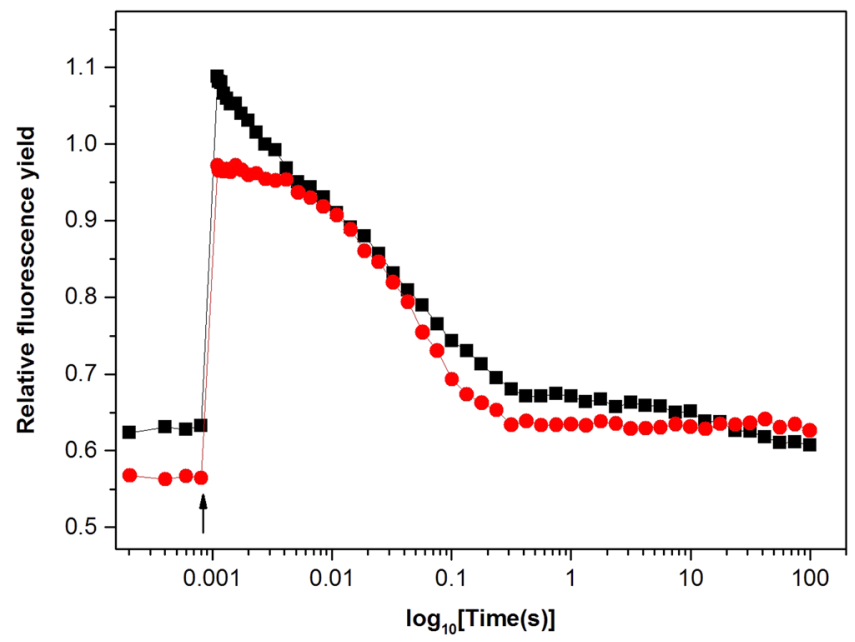

Figure 4. Flash induced fluorescence decay kinetics from the re-oxidized double reduced PS II membrane samples. Traces indicate the fluorescence yield changes after a single flash in the presence (red) or in the absence (black) of DCMU.

We can also conclude that, not surprisingly, a substantial amount of $\mathrm{Q}_{\mathrm{A}}{ }^{-}$remained reduced also after the re-oxidation protocol. This is shown by the high $F_{0}(0.63)$ in our fluorescence measurement (Fig. 4, black trace). Furthermore, there seems to remain very few PS II centres with bound $\mathrm{Q}_{\mathrm{B}}$ after the re-oxidation procedure. This can be concluded from comparison of the kinetic traces in the presence and absence of the inhibitor DCMU. Addition of DCMU, which inhibits electron transfer from $\mathrm{Q}_{\mathrm{A}}$ to $\mathrm{Q}_{\mathrm{B}}$, removed a small fast component from the fluorescence decay curve (Fig. 4, red trace). This fast phase most likely reflects electron transfer from $\mathrm{Q}_{\mathrm{A}}$ to a remaining bound $\mathrm{Q}_{\mathrm{B}}$. Normally this fast decay phase dominates in PSII and its small amplitude in our samples clearly indicates that there is very little $\mathrm{Q}_{\mathrm{B}}$ remaining after the double reduction/re-oxidation treatments. The rest of the decay is similar to the decay observed in presence of DCMU and again reflects $\mathrm{Y}_{\mathrm{Z}}{ }^{\bullet} \mathrm{Q}_{\mathrm{A}}{ }^{-}$recombination.

Induction of the spin polarized ${ }^{3} \mathrm{P} 680$ under white and far-red light excitation. The spin polarized triplet state ${ }^{3} \mathrm{P}_{680}$ is a useful probe to the physical environment and photochemistry of $\mathrm{P}_{680}$ and the primary 


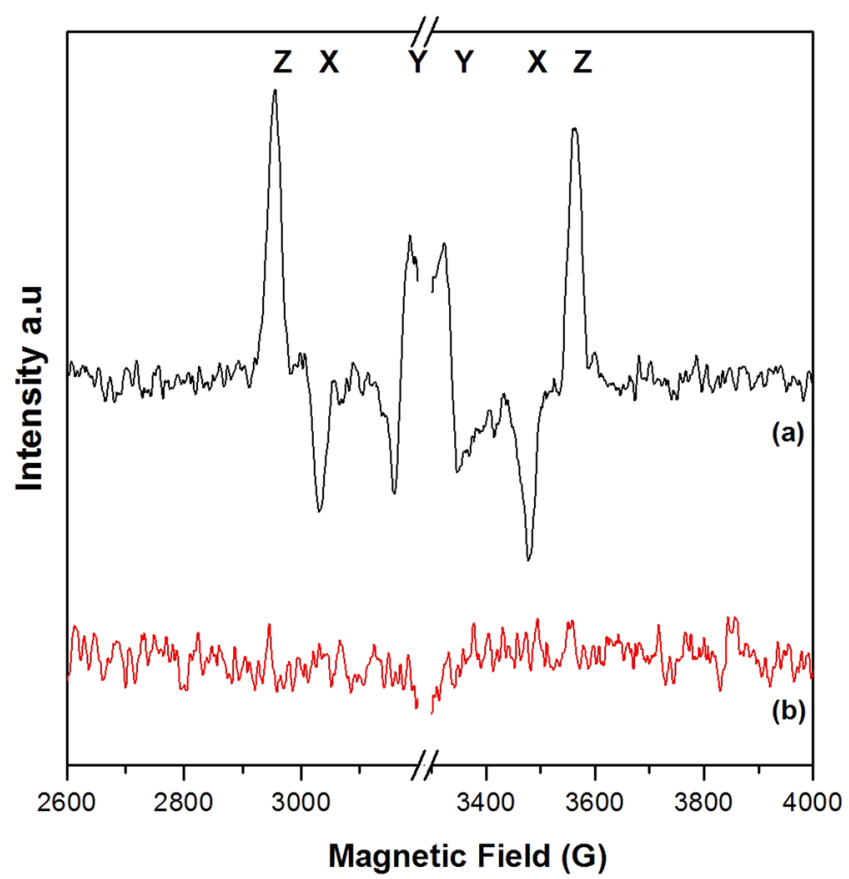

Figure 5. Light minus dark difference EPR spectra showing the formation (or not) of the spin-polarized ${ }^{3} \mathrm{P}_{680}$ in PS II samples after reduction with sodium dithionite and benzyl viologen. The light spectra were acquired under continuous illumination at $5 \mathrm{~K}$ with (a) white light and (b) far-red light $(732 \mathrm{~nm})$ EPR conditions: microwave power $63 \mu \mathrm{W}$, microwave frequency $9.139 \mathrm{GHz}$, modulation amplitude $30 \mathrm{G}$, temperature, $5 \mathrm{~K}$.

radical pair in PSII ${ }^{36}$. In intact PSII, ${ }^{3} \mathrm{P}_{680}$ is not observable with EPR spectroscopy ${ }^{37}$. However, when $\mathrm{Q}_{\mathrm{A}}$ is either removed (in for example the D1/D2/Cyt $b_{559}$ preparation) ${ }^{37,38}$ or double reduced either by chemical treatment ${ }^{27-29}$ or extensive illumination under anaerobic conditions ${ }^{39}$, the spin polarized EPR signal from ${ }^{3} \mathrm{P}_{680}$, can be observed as a result of recombination of the $\mathrm{P} 680^{+} \mathrm{Pheo}^{-}$charge pair.

Here, we have investigated the formation of ${ }^{3} \mathrm{P}_{680}$ in samples where $\mathrm{Q}_{\mathrm{A}}$ has been chemically double reduced. Figure 5 depicts the "light minus dark" difference EPR spectra from the spin-polarized triplet state of ${ }^{3} \mathrm{P}_{680}$ obtained from PSII membranes with double reduced $\mathrm{Q}_{\mathrm{A}}$, when illuminated by continuous white light (spectrum (a)) at $5 \mathrm{~K}$. Our chemical reduction procedure converts $\mathrm{Q}_{\mathrm{A}}$ to $\mathrm{Q}_{\mathrm{A}}{ }^{2-}$, which is then protonated to form $\mathrm{Q}_{\mathrm{A}} \mathrm{H}_{2}{ }^{27,29}$. After excitation with light, no forward electron transfer from $\mathrm{Pheo}^{-}$is possible. Instead, the charge-separated state $\mathrm{P}_{680}{ }^{+} \mathrm{Pheo}^{-}$will decay through recombination. However, it is long-lived enough to allow spin dephasing, thereby allowing formation of the triplet form of the radical pair, the so called spin-polarized ${ }^{3} \mathrm{P}_{680}$ state as follows ${ }^{36,40}$ :

$$
\mathrm{P}_{680} \text { Pheo } \Leftrightarrow \mathrm{P}_{680}{ }^{*} \text { Pheo } \Leftrightarrow\left[\mathrm{P}_{680}{ }^{+} \text {Pheo }{ }^{-}\right] \text {Spin dephasing \& recombination } \Rightarrow^{3}\left[\mathrm{P}_{680}\right]
$$

Hence, at low temperatures $(5 \mathrm{~K})$, the triplet state of the primary donor, ${ }^{3} \mathrm{P}_{680}$, is formed with high yield ${ }^{27,29,38,41}$.

From orientation studies of the ${ }^{3} \mathrm{P}_{680}$ EPR signal it was concluded that it is localized on a Chl molecule (unidentified at that time) most likely to be $\mathrm{Chl}_{\mathrm{D} 1}$ (in the present structural nomenclature, see Fig. 1$)^{38,42,43}$. It is known that the product of the primary charge separation in visible light is $\mathrm{P}_{\mathrm{D} 1}{ }^{+} \mathrm{Pheo}^{-}$. Therefore, the localization of the ${ }^{3} \mathrm{P}_{680}$ on another $\mathrm{Chl}$ molecule than $\mathrm{P}_{\mathrm{D} 1}$ is unexpected. The phenomenon has been explained by two alternative mechanisms. Either the triplet state migrates from $\mathrm{P}_{\mathrm{D} 1}$ to $\mathrm{Chl}_{\mathrm{D} 1}$ after its formation or it is the Chl cation $\left(\mathrm{P}_{\mathrm{D} 1}{ }^{+}\right)$ that moves to $\mathrm{Chl}_{\mathrm{D} 1}$ (forming $\mathrm{Chl}_{\mathrm{D} 1}{ }^{+}$) prior to ${ }^{3} \mathrm{P}_{680}$ formation ( ${ }^{38}$ and refs. therein).

As shown in Fig. 5, spectrum (a), the characteristic spin-polarized EPR signal from ${ }^{3} \mathrm{P}_{680}$ was observed under white light illumination. The spectrum is in agreement with previously published EPR spectra of ${ }^{3} \mathrm{P}_{680}{ }^{27,29,36-38}$. The triplet EPR spectrum depicts a low-field to high-field AEEAAE (Absorption $=\mathrm{A}$, Emission $=\mathrm{E}$ ) polarization pattern spanning $\sim 650 \mathrm{G} . \mathrm{X}, \mathrm{Y}$ and $\mathrm{Z}(\mathrm{D}>0, \mathrm{E}<0)$ indicate the field positions of the respective canonical orientations for the zero field splitting tensor of the triplet state.

We have also intensively searched for the formation of ${ }^{3} \mathrm{P}_{680}$ in an identical sample after illumination in the EPR cavity with far-red light. Interestingly, as depicted in Fig. 5, spectrum (b), no spin polarized EPR signal from ${ }^{3} \mathrm{P}_{680}$ could be detected under these conditions. This obvious difference between visible and far-red light excitation is intriguing as our control measurements clearly indicate that: i) our samples were indeed able to form ${ }^{3} \mathrm{P}_{680}$ in visible light (Fig. 5, spectrum $a$ ) and ii) were indeed able to perform charge separation and a multitude of electron transfer reactions on both the donor and the acceptor side of PS II in both visible and far-red light (Figs 2-4).

Accumulated Spectra of spin polarized ${ }^{3} P_{680}$. It is possible that the lack of the ${ }^{3} \mathrm{P}_{680}$ EPR signal under far-red light reflects the complete absence of ${ }^{3} \mathrm{P}_{680}$ formation. However, it could also be caused by a very fast ${ }^{3} \mathrm{P}_{680}$ decaying species not detectable under standard CW EPR conditions. To test this, we therefore accumulated 

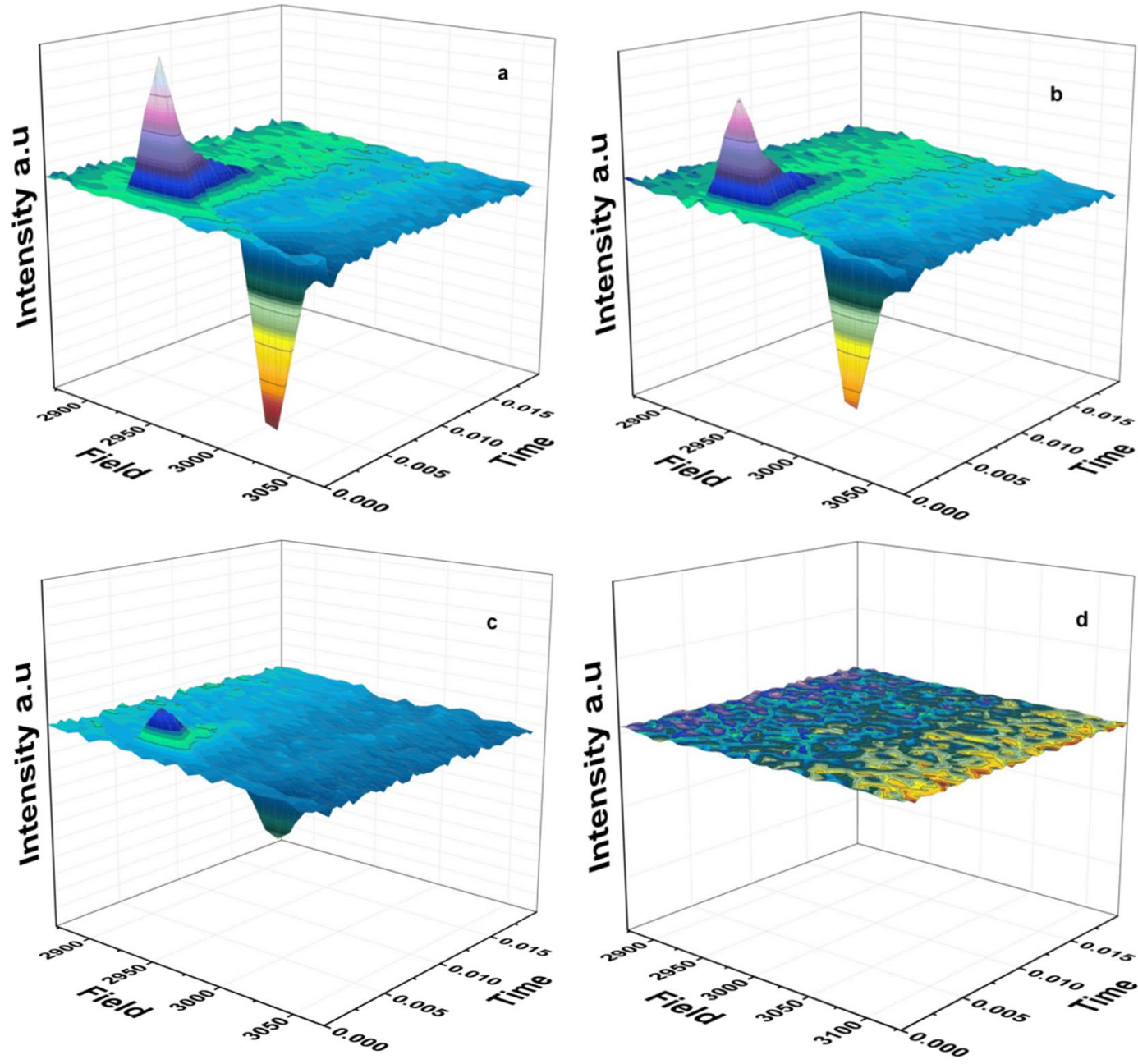

Figure 6. Flash-associated transient $3 \mathrm{D}$ spectra of spin polarized ${ }^{3} \mathrm{P}_{680}$ at $532 \mathrm{~nm}(40 \mathrm{~mJ})(\mathbf{a}), 610 \mathrm{~nm}(35 \mathrm{~mJ})$ (b), $689 \mathrm{~nm}(35 \mathrm{~mJ})(\mathbf{c})$ and $730 \mathrm{~nm}(20 \mathrm{~mJ})(\mathbf{d})$ (numbers in parentheses denote the laser flash power), laser flash excitation. Each spectrum represents the accumulation of 1000 transients at 32 field positions (low-field peaks) respectively, with a delay time before flash application of $1 \mathrm{~ms}$, at $5 \mathrm{~K}$. The EPR signal was detected $\sim 50 \mu$ s after laser excitation with a detection time window of $20 \mathrm{~ms}$. EPR conditions were as follow: microwave power $63 \mu \mathrm{W}$, microwave frequency $9.139 \mathrm{GHz}$, receiver time constant $0.08 \mathrm{~ms}$, modulation amplitude $35 \mathrm{G}$, temperature, $5 \mathrm{~K}$.

flash-associated spectra at $532 \mathrm{~nm}, 610 \mathrm{~nm}, 689 \mathrm{~nm}, 730 \mathrm{~nm}, 750 \mathrm{~nm}$ and $790 \mathrm{~nm}$ at $5 \mathrm{~K}$, recorded with a flash frequency of $5 \mathrm{~Hz}$. Figure 6 shows the flash-associated transients recorded in the low-field region of the ${ }^{3} \mathrm{P}_{680}$ spectrum (2850-3150 G) upon $532 \mathrm{~nm}(\mathrm{a}), 610 \mathrm{~nm}(\mathrm{~b}), 689 \mathrm{~nm}$ (c) and $730 \mathrm{~nm}$ (d) laser flash excitation. The intensity of the spin-polarized ${ }^{3} \mathrm{P}_{680}$ features is high under $532 \mathrm{~nm}$ and $610 \mathrm{~nm}$ excitation and decreased by more than $50 \%$ under $689 \mathrm{~nm}$ excitation. Ultimately, there is no EPR signal from ${ }^{3} \mathrm{P}_{680}$ detected even with our fastest available time resolution and after extensive illumination with far-red laser flash excitation $(730-790 \mathrm{~nm})($ Fig. 7$)$. It is also important to point out that the decay kinetics of respectively the $\mathrm{X}$ and $\mathrm{Z}$ peaks are identical irrespective of the induction wavelength between $532 \mathrm{~nm}$ and $689 \mathrm{~nm}$ (Fig. 7a,b). The decay kinetics are, however, faster for the X peak than for the $\mathrm{Z}$ peak similar to earlier observations ${ }^{36}$. At $\geq 730 \mathrm{~nm}$ no peaks were observed.

\section{Discussion}

The understanding of how low energy excited states contribute to PSII photochemistry continues to be a challenging task $\mathrm{k}^{44}$. This is especially true if specific charge transfer bands, not detectable by conventional spectroscopy, are responsible for this type of photochemistry ${ }^{44,45}$. In this study we are analysing these phenomena, by using EPR based, comparative product analysis (see also ref. ${ }^{45}$ ) using the characteristic EPR signal of spin polarized ${ }^{3} \mathrm{P}_{680}$ as a probe for the primary charge separation at low temperatures.

In our first publication we showed, for the first time, that PSII operates much further to the far-red region (by $100 \mathrm{~nm}$ ) than was believed before. We have shown that efficient secondary electron transfer reactions take place under these conditions, including turnover of the $O E C$, reduction of the primary and secondary quinones, oxidation of the secondary donor $\mathrm{Tyr}_{\mathrm{Z}}$ and reduction of the primary donor, Phe, using far-red (up to $\geq 800 \mathrm{~nm}$ ) photons. This was an interesting observation and in an earlier study we proposed an alternative charge separation 

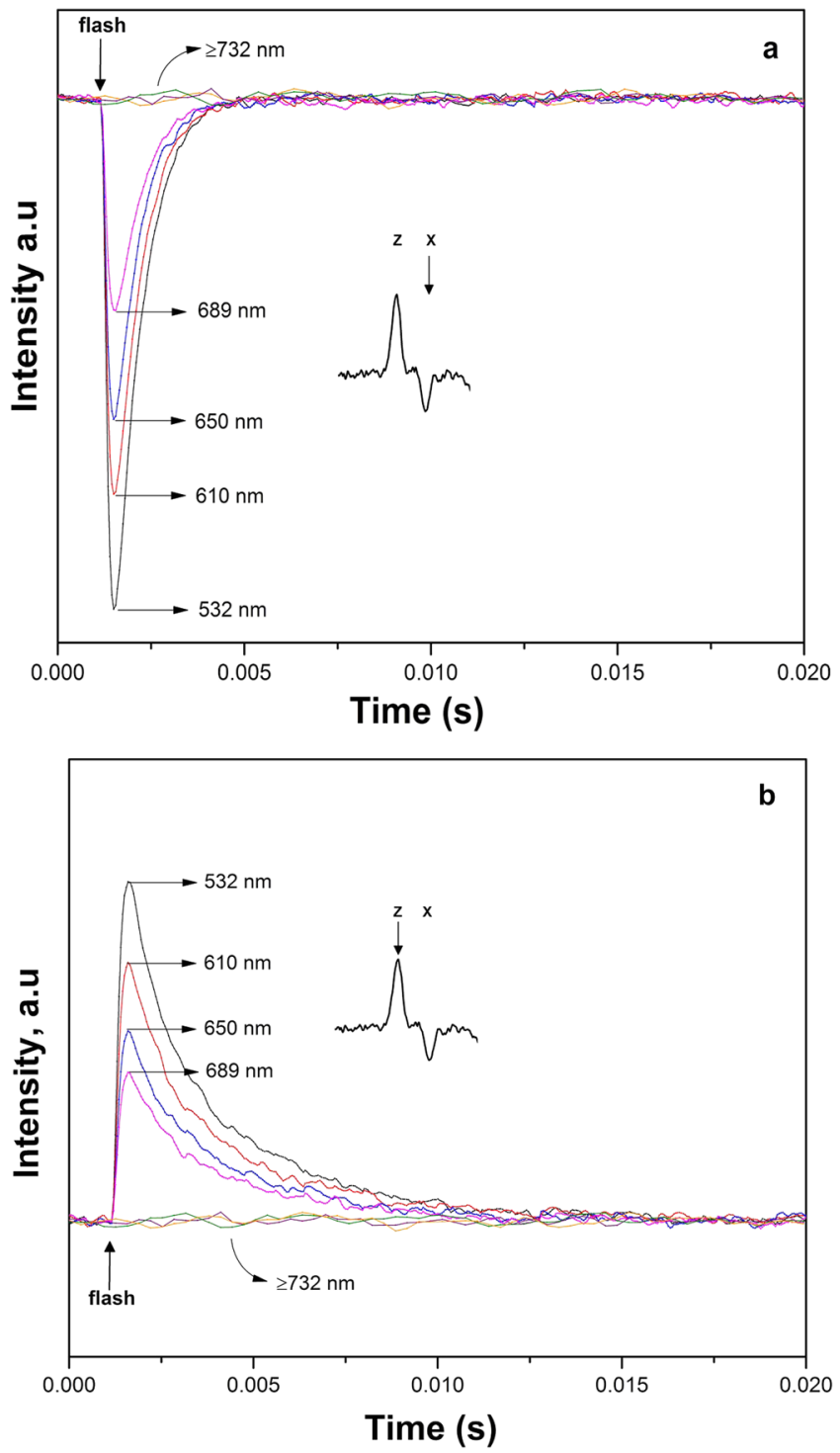

Figure 7. Spin polarized ${ }^{3} \mathrm{P}_{680}$ flash-associated transient decay traces upon $532 \mathrm{~nm}$ (black), $610 \mathrm{~nm}$ (red), $650 \mathrm{~nm}$ (blue), $689 \mathrm{~nm}$ (pink), $730 \mathrm{~nm}$ (purple), $750 \mathrm{~nm}$ (orange) and $790 \mathrm{~nm}$ (green) flash excitation recorded at fixed field positions $\mathrm{X}(\mathbf{a})$ and $\mathrm{Z}(\mathbf{b})$ of the low field region of the ${ }^{3} \mathrm{P}_{680}$ EPR spectrum (see inserts and Fig. 4). The traces are the result of 1000 accumulated transients at 5 K. EPR conditions as in Fig. 5.

reaction under far-red conditions involving a low energy primary donor, denoted $\mathrm{X}^{*}$, which was able to drive both $\mathrm{Pheo}^{-}$reduction and $\mathrm{Y}_{\mathrm{Z}}$ oxidation $^{22}$.

This suggestion was further substantiated in a study of low temperature $(5 \mathrm{~K})$ electron transfer on the donor side of PS II. To elaborate, we found that far-red light preferentially promoted electron transfer from $\mathrm{Y}_{\mathrm{Z}}$ to the primary donor. In contrast, visible light promoted almost equal electron transfer from either $\mathrm{Y}_{Z}$ or the Cyt $b_{559} /$ $\mathrm{Chl}_{\mathrm{Z}} / \mathrm{Car}_{\mathrm{D} 2}$ secondary pathway. The partition ratio between the two electron donor pathways was thus wavelength dependent, $\mathrm{Y}_{\mathrm{Z}}$ being the better donor after far-red excitation ${ }^{25}$.

An important implication of this work, discussed in ${ }^{22,25}$ is that the far-red photochemistry is triggered by weakly absorbing charge transfer states among the core pigments in PSII and not by the well-known bands at $680 \mathrm{~nm}\left(\mathrm{P}_{\mathrm{D} 1}\right)$ or $684 \mathrm{~nm}\left(\mathrm{Chl}_{\mathrm{D} 1}\right)$.

In our present manuscript, we are getting even closer to the primary charge pair, $\mathrm{P}_{680}+\mathrm{Pheo}^{-}$, showing that the primary donor is indeed different. Thus, our, step wise refined, product analysis technique provides a unique approach to study the far-red photochemistry in PSII and to cast further light on this phenomenon by studying the primary electron donor in PS II, $\mathrm{P}_{680}$, directly. Our result is surprising. As described previously, the spin polarized EPR signal from ${ }^{3} \mathrm{P}_{680}$ can be observed from PS II centres where $\mathrm{Q}_{\mathrm{A}}$ has been doubly reduced (or it is absent). It has earlier been shown that its formation using white light is almost quantitative ${ }^{27,36}$. In our hands, the ${ }^{3} \mathrm{P}_{680}$ EPR signal is large and fairly consistent in amplitude, when PS II is exposed to light in the visible region. However, in the far-red, at wavelengths $\geq 730 \mathrm{~nm}$ the illumination does not induce any observable ${ }^{3} \mathrm{P}_{680}$ EPR signal at all. 
There can be several reasons for the above phenomenon. To find the answers and formulate our hypothesis, certain questions must be addressed: (i) Is the electron hole on the primary donor not forming at all under far-red light illumination? (ii) If it was formed in far-red light, would the ${ }^{3} \mathrm{P}_{680}$ decay too fast and escape detection? (iii) Do we trigger an alternative charge separation pathway by far-red light, hence creating a different, low energy, state as suggested in ref. ${ }^{20}$ ? (iv) Is the cation located at a different $\mathrm{Chl}$ if compared to the visible light as hypothesized in ref. ${ }^{23}$ ? If yes, then the recombination between the primary donor and $\mathrm{Pheo}^{-}$occurs too fast to allow ${ }^{3} \mathrm{P}_{680}$ formation after far-red illumination.

First, we can exclude that this particular type of PS II sample (sodium dithionite/benzyl viologen reduced) is not able to carry out any charge separation in the far-red at all, since we in fact can photoaccumulate the $\mathrm{Pheo}^{-}$ radical in the majority of PS II under illumination with $730 \mathrm{~nm}$ light. Therefore, an electron hole on the $\mathrm{P}_{680}$ entity is formed after excitation by far-red light. In that case, recombination between Pheo- and $\mathrm{P}_{680}{ }^{+}$will take place, either via or without the formation of ${ }^{3} \mathrm{P}_{680}$.

Second, in far-red light we observe no spin polarized ${ }^{3} \mathrm{P}_{680}$ EPR signal. However, in the event where ${ }^{3} \mathrm{P}_{680}$ is anyway formed by the far-red light, it is possible that it decays faster than we can detect it, in contrast to the situation in the visible part of the spectrum. An attempt has been made to investigate this possibility further by our kinetic measurements of ${ }^{3} \mathrm{P}_{680}$ induced by different light wavelengths. Here we report identical decay kinetics between the different light regimes where we could observe the ${ }^{3} \mathrm{P}_{680}$ in the visible light spectrum. However, we were not able to observe any ${ }^{3} \mathrm{P}_{680}$ formation above $700 \mathrm{~nm}$, despite our sub-millisecond time resolution. We argue that there is little reason to suggest that ${ }^{3} \mathrm{P}_{680}$ formed by far-red light should decay too fast to allow its detection. Instead, we propose that the far-red light illumination, although it efficiently drives charge separation and creation of a primary radical pair $\left[\mathrm{P}_{680}{ }^{+} \mathrm{Phe}^{-}\right]$, does not result in the formation of the spin polarized EPR signal from ${ }^{3} \mathrm{P}_{680}$. Since $\mathrm{Pheo}^{-}$is the same in both cases, it is the nature of the Chl cation, $\left(\mathrm{Chl}^{+}\right)$that differs after excitation with visible or far-red light.

This observation also has important implications with respect to the earlier orientation studies of the spin-polarized ${ }^{3} \mathrm{P}_{680}$ EPR signal formed by visible light (see above) ${ }^{38,42,43}$. From our results, we can rule out that the triplet state is formed after migration of the cation from one monomeric Chl to another (from $\mathrm{P}_{\mathrm{D} 1}$ to $\mathrm{Chl}_{\mathrm{D} 1}$ ). In this case we would have observed the ${ }^{3} \mathrm{P}_{680}$ EPR signal under both illumination regimes since the triplet would have been formed from the same $\mathrm{Chl}_{\mathrm{D} 1}{ }^{+} \mathrm{Pheo}^{-}$charge pair. Instead, detection of the signal under visible light only strongly indicates involvement of different charge pairs under the two illumination regimes with the triplet state only being formed by the $\mathrm{P}_{\mathrm{D} 1}{ }^{+} \mathrm{Pheo}^{-}$charge pair recombination.

Third, we have recently demonstrated preferential electron transfer from $\mathrm{Y}_{\mathrm{Z}}$ in comparison to very weak electron transfer from the Cyt $b_{559} / \mathrm{Chl}_{\mathrm{Z}} / \mathrm{Car}_{\mathrm{D} 2}$ side donors under far-red light illumination at $5 \mathrm{~K}^{25}$. To explain this, we hypothesized the existence of an alternative charge separation pathway under far-red light involving the oxidized primary donor after charge separation residing on $\mathrm{Chl}_{\mathrm{D} 1}$ rather than $\mathrm{P}_{\mathrm{D} 1}{ }^{25}$. Thus, we suggest that upon far-red excitation, a new pathway is activated. We denote this as the the $\mathrm{Chl}_{\mathrm{D} 1}$ pathway (Fig. 1). Here, a lower energy excited state $\left[\mathrm{Chl}_{\mathrm{D} 1} \text { Pheo] }\right]^{*}$ is formed, most probably corresponding to the proposed $\mathrm{X}^{*}$ in ref. ${ }^{20}$, which would then lead to a different radical pair after the charge separation, $\left[\mathrm{Chl}_{\mathrm{D} 1}{ }^{+} \mathrm{Pheo}^{-}\right]$(Fig. 1).

Lastly, the lack of observable triplet signal implies that the recombination from $\mathrm{Pheo}^{-}$is too fast to allow spin dephasing. This suggests that the electron hole is presumably residing on $\mathrm{Chl}_{\mathrm{D} 1}$ instead of $\mathrm{P}_{\mathrm{D} 1}$. Chl $\mathrm{Cl}_{\mathrm{D} 1}$ is much closer to Pheo than $\mathrm{P}_{\mathrm{D} 1}(5 \AA \text { vs } 8.1 \AA)^{26}$. This shorter distance would probably facilitate faster recombination of the charge pair $\mathrm{Chl}_{\mathrm{D} 1}{ }^{+} \mathrm{Pheo}^{-}$. Hence, we propose that the far-red light preferentially drives charge separation to Pheo from $\mathrm{Chl}_{\mathrm{D} 1}$ in the reaction center (Fig. 1). Since $\mathrm{Chl}_{\mathrm{D} 1}{ }^{+}$and $\mathrm{Pheo}_{\mathrm{D} 1}{ }^{-}$are in close proximity, we propose that recombination occurs faster than between the radical pair $\left[\mathrm{P}_{\mathrm{D} 1}{ }^{+} \mathrm{Pheo}^{-}\right]$found in visible light. Thus, the $\left[\mathrm{Chl}_{\mathrm{D} 1}{ }^{+} \mathrm{Pheo}^{-}\right]$radical pair probably recombines back to the ground state prior to spin dephasing can occur. Consequently no spin polarized ${ }^{3} \mathrm{P}_{680}$ is formed at any of the PSII centres.

It is generally thought that at low temperatures the cation in the primary radical pair is stabilized on $\mathrm{P}_{\mathrm{D} 1}$ (Fig. 1 ${ }^{40,46-50}$, which is not far from neither $\mathrm{Y}_{\mathrm{Z}}$ nor the Cyt $b_{559} / \mathrm{Chl}_{\mathrm{Z}} / \mathrm{Car}_{\mathrm{D} 2}$ secondary pathway. Therefore they compete, and both are oxidized in substantial yield at very low temperatures ${ }^{25}$. Contrary, the localization of the primary electron hole on $\mathrm{Chl}_{\mathrm{D} 1}$ rather than $\mathrm{P}_{\mathrm{D} 1}$ under far-red light was discussed in ref. ${ }^{23}$. It was proposed that with the formation of the primary electron hole on $\mathrm{Chl}_{\mathrm{D} 1}$, the location of $\mathrm{Chl}_{\mathrm{D} 1}$ being relatively closer to $\mathrm{Y}_{\mathrm{Z}}$ but much more distant from the Cyt $b_{559} / \mathrm{Chl}_{\mathrm{Z}} / \mathrm{Car}_{\mathrm{D} 2}$ secondary pathway, could explain at least qualitatively, the preference for oxidation of $\mathrm{Y}_{\mathrm{Z}}$ over Cyt $b_{559} / \mathrm{Chl}_{\mathrm{Z}} / \mathrm{Car}_{\mathrm{D} 2}$.

The existence of parallel charge separation pathways in PSII under different light regimes and under physiological and cryogenic conditions has been suggested and discussed before ${ }^{50-55}$. In 2009 Thapper et al. ${ }^{22}$ suggested the formation of a low-energy state denoted $\mathrm{X}^{*}$ in PS II after far-red light excitation at room temperature. Although functioning at a lower energetic threshold compared to $\mathrm{P}_{680}{ }^{*}$, it was shown to effectively trigger the charge separation, reduce $\mathrm{Pheo}$ and oxidize $\mathrm{Y}_{\mathrm{Z}}$ up to $\sim 800 \mathrm{~nm}$. More recently, transient absorption spectroscopy at $77 \mathrm{~K}$, suggested the existence of two different charge separation pathways in PS $\mathrm{II}^{50}$. These were dependent on the light induced protein configuration in PSII core complexes. In one path, denoted the $\mathrm{Chl}_{\mathrm{D} 1}$ path, the charge separation events were proposed to involve an interaction between $\mathrm{Chl}_{\mathrm{D} 1}$ and $\mathrm{Pheo}$, and follow the sequence $\left(\mathrm{Chl}_{\mathrm{D} 1} \mathrm{Pheo}\right)^{*} \Rightarrow\left(\mathrm{Chl}_{\mathrm{D} 1}{ }^{+} \mathrm{Pheo}^{-}\right) \Rightarrow\left(\mathrm{P}_{\mathrm{D} 1}{ }^{+} \mathrm{Pheo}^{-}\right)$. In the second pathway, denoted the $\mathrm{P}_{\mathrm{D} 1}$ path, a charge transfer state $\mathrm{P}_{\mathrm{D} 1} \mathrm{P}_{\mathrm{D} 2}$ is excited and the charge separation events were suggested to follow an alternative sequence $\left(\mathrm{P}_{\mathrm{D} 1}\right.$ $\left.\mathrm{P}_{\mathrm{D} 2} \mathrm{Pheo}\right)^{*} \Rightarrow\left(\mathrm{P}_{\mathrm{D} 1}{ }^{+} \mathrm{P}_{\mathrm{D} 2} \mathrm{Chl}_{\mathrm{D} 1}{ }^{-}\right) \Rightarrow\left(\mathrm{P}_{\mathrm{D} 1}{ }^{+} \mathrm{P}_{\mathrm{D} 2} \mathrm{Pheo}^{-}\right)^{52,54,55}$. The proposal that the two pathways are actually of an antagonistic nature and the effectiveness of each of the pathways essentially depends on recognition of energetic disorder, fits with our observations.

When a low energy photon in the far-red is used for excitation, the subsequent energetic disorder causes the preferential excitation to be strongly localized at $\mathrm{Chl}_{\mathrm{D} 1}$, thus allowing for charge separation to take place with the first charge separated state being $\mathrm{Chl}_{\mathrm{D} 1}{ }^{+} \mathrm{Pheo}^{-}$. This localized state should be energetically lower than the $\mathrm{P}_{\mathrm{D} 1}$ $\mathrm{P}_{\mathrm{D} 2}$ charge transfer state, which is in agreement with the results of the present study. Thus, we propose that two 
pathways for primary charge separation exist in parallel in PS II reaction centres and their excitation and activation is wavelength dependent (Fig. 1).

\section{Concluding Remarks}

Here, we have provided further insight into the location of the primary charge separation upon far-red light excitation of PS II, using the EPR signal of the spin polarized ${ }^{3} \mathrm{P}_{680}$ as a probe. We demonstrate that, under far-red light illumination, the spin polarized ${ }^{3} \mathrm{P}_{680}$ is not formed, although we show that the primary charge separation is still occurring at these conditions. We propose that this is because under far-red light excitation, the primary electron hole is localized on $\mathrm{Chl}_{\mathrm{D} 1}$, rather than on $\mathrm{P}_{\mathrm{D} 1}$ (Fig. 1). The formation of the lower energy excited state $\mathrm{Chl}_{\mathrm{D} 1} \mathrm{Pheo}^{*}$ by far-red light, leads to the $\left[\mathrm{Chl}_{\mathrm{D} 1}{ }^{+} \mathrm{Pheo}^{-}\right]$primary charge pair. The close proximity of these two cofactors, allows fast recombination to the ground state before spin dephasing can occur, hence the ${ }^{3} \mathrm{P}_{680}$ cannot be formed.

The fact that identical samples have demonstrated charge separation upon both far-red and visible light excitation further supports our hypothesis that two pathways for primary charge separation exist in parallel in PS II reaction centres. They are excited and activated dependent of the wavelength applied. In the visible part of the spectrum the first product of the charge separation is normally considered to be $\mathrm{P}_{\mathrm{D} 1}{ }^{+} \mathrm{Pheo}^{-}$.

In stark contrast, we hypothesize that far-red illumination results in the $\mathrm{Chl}_{\mathrm{D} 1}{ }^{+} \mathrm{Pheo}^{-}$radical pair. The latter recombines without formation of the ${ }^{3} \mathrm{P}_{680}$, thereby explaining the results in the present contribution. When far-red light is applied to intact PS II however, the oxidizing electron hole, presumably $\mathrm{Chl}_{\mathrm{D} 1}{ }^{+}$, preferentially drives electron transfer from $\mathrm{Y}_{\mathrm{Z}}$ and consequently the $\mathrm{CaMn}_{4}$ cluster. As described earlier, the $\mathrm{Yz}_{\mathrm{z}} \mathrm{CaMn}_{4}$ pathway is preferred over the Cyt $b_{559} / \mathrm{Chl}_{\mathrm{Z}} / \mathrm{Car}_{\mathrm{D} 2}$ pathway at low temperatures due to the favourable location of $\mathrm{Chl}_{\mathrm{D} 1} \mathrm{vs}$ $\mathrm{Y}_{\mathrm{Z}}$ over $\mathrm{Chl}_{\mathrm{Z}}^{21}$.

\section{Materials and Methods}

PSII membrane preparation. Spinach (Spinacia oleracia) was grown hydroponically as described previously at $20^{\circ} \mathrm{C}$ under cool white fluorescent light (Osram Powerstar HQI-400W/DV dysprosium lamp, intensity $300 \mu \mathrm{Em}^{-2} \mathrm{~s}^{-1}$ ), with light-dark periods of $12 \mathrm{~h}^{33}$. Oxygen evolving PSII enriched membranes (BBY-type) were prepared according to previously published procedure ${ }^{56,57}$. The membrane particles were re-suspended in a final buffer containing $400 \mathrm{mM}$ Sucrose, $15 \mathrm{mM} \mathrm{NaCl}, 3 \mathrm{mM} \mathrm{MgCl}_{2}$ and $25 \mathrm{mM} \mathrm{MES}-\mathrm{NaOH} \mathrm{pH}$ 6.1, and frozen as beads at $-80^{\circ} \mathrm{C}$, at a Chl concentration of $6 \mathrm{mg} / \mathrm{ml}$.

Chemical reduction and re-oxidation of PS II. In order to obtain reaction centers with doubly reduced $\mathrm{Q}_{\mathrm{A}}$, PS II membranes were exposed to reducing conditions as described in ${ }^{27,28}$ with modifications as in ${ }^{29}$. Specifically, upon addition of $40 \mathrm{mM}$ sodium dithionite, $100 \mu \mathrm{M}$ benzyl viologen and $3 \mathrm{mM}$ EDTA under anaerobic conditions, dark-adapted PS II membranes at a Chl concentration of $6 \mathrm{mg} / \mathrm{ml}$, were incubated in the dark for $5 \mathrm{hrs}$ to achieve the double reduction of $\mathrm{Q}_{\mathrm{A}}$ to $\mathrm{Q}_{\mathrm{A}} \mathrm{H}_{2}$. All incubations were carried out in argon flushed EPR tubes. Upon completion of the incubation time, the EPR samples were frozen within $1 \mathrm{sec}$ in a $200 \mathrm{~K}$ dry ice/ethanol bath and subsequently transferred into $\mathrm{N}_{2}(\mathrm{l})$ before the measurements.

"Reversed" samples where $\mathrm{Q}_{A} \mathrm{H}_{2}$ was re-oxidized, were prepared according to previously published procedures $^{27}$. The doubly reduced samples were initially washed three times $(15000 \times \mathrm{g}, 15 \mathrm{~min}$ cycle $)$ with argon flushed buffer containing $400 \mathrm{mM}$ Sucrose, $15 \mathrm{mM} \mathrm{NaCl}, 3 \mathrm{mM} \mathrm{MgCl}_{2}$ and $25 \mathrm{mM} \mathrm{MES}-\mathrm{NaOH} \mathrm{pH}$ 6.1, to remove sodium dithionite and benzyl viologen. They were then re-oxidized with $5 \mathrm{mM} \mathrm{K}_{3} \mathrm{Fe}(\mathrm{CN})_{6}$, which was subsequently removed by repeating the washing procedure three times with final buffer, as described above. All washing steps were performed in complete darkness and at $4^{\circ} \mathrm{C}$.

Illumination procedures. The spin polarized ${ }^{3} \mathrm{P}_{680}$ EPR signal was induced by illumination of the samples in the EPR cavity with white or far-red light at $5 \mathrm{~K}$. For continuous illumination, white light, filtered through a $5 \mathrm{~cm}$-thick copper sulphate solution heat filter, was provided by an $800 \mathrm{~W}$ halogen projector lamp. Far-red light illumination was achieved by the use of a custom made LED module, emitting continuous light centred at $732 \mathrm{~nm}$. Appropriate long pass filters were used so as to ensure blocking of transmission of any stray UV light (CC4) as well as transmission of light $<725 \mathrm{~nm}$ (RG9). Transient formation and accumulation of the spin polarized ${ }^{3} \mathrm{P}_{680}$ EPR signal was studied by applying laser flashes into the EPR cavity, from a Spectra Physics PRO-290 Q-switched Nd:YAG laser (6 ns flash, $5 \mathrm{~Hz}$ flash frequency) equipped with a Spectra Physics Quanta Ray MOPO 730 optical parametric oscillator.

The Split $S_{1}$ signal was obtained by white or far-red continuous wave light illumination at $5 \mathrm{~K}$, as in ${ }^{58}$.

For the measurements of the Pheo- ${ }^{-}$radical, doubly reduced PS II membranes $(6.0 \mathrm{mg} \mathrm{Chl} / \mathrm{ml})$ were subjected to white or far-red $(732 \mathrm{~nm})$ continuous wave light illumination as described earlier ${ }^{30-32}$, at $20^{\circ} \mathrm{C}$, for 6 and 10 minutes respectively at room temperature. Thereafter, the samples were frozen within 1 sec in a $200 \mathrm{~K}$ dry ice/ethanol bath and subsequently transferred into $\mathrm{N}_{2}(\mathrm{l})$ before the measurements. The size of the EPR spectrum of the formed $\mathrm{Pheo}^{-}$radical was compared by double integration to the size of the EPR spectrum from $\mathrm{Y}_{\mathrm{D}}{ }^{\bullet}$ in a corresponding sample prior to double reduction, allowing us to quantify the function of the primary charge separation in the double reduced samples.

Fluorescence measurements. Flash-induced fluorescence decay measurements were performed at room temperature at a sample concentration of $20 \mu \mathrm{g} \mathrm{Chl} / \mathrm{ml}$. PS II membranes were dark adapted for $5 \mathrm{~min}$ and measurements were performed in the presence or absence of $20 \mu \mathrm{M}$ DCMU. The variable fluorescence decay traces were recorded with a FL3000 double modulated fluorometer (PSI Photon Systems Instruments, Czech Republic) according to ${ }^{59}$. The first data point was taken $100 \mu \mathrm{s}$ after the actinic flash. Measuring flashes were then applied logarithmically eight times per decade in a time range up to $100 \mathrm{~s}^{60}$. 
EPR spectroscopy. X-band EPR measurements were performed with an Elexsys E580 (Bruker BiosSpin) equipped with a standard cavity (ST 4102). All measurements were performed at low temperature that was achieved with the use of a helium flow cryostat and an ICT-4 temperature controller (Oxford Instruments, UK). The time-resolved EPR (TREPR) measurements were performed with the use of the ADF fast digitizer board ( $2 \mathrm{MHz}$ fixed sampling rate). Signal acquisition was synchronized with $5 \mathrm{~Hz}$ laser flashes using a LC880 TTL pulse generator (100 MHz internal clock) (LabSmith, Livermore, California). An accessory transformer was used to amplify the TTL pulses to the $5 \mathrm{~V}$ amplitude required for triggering the laser lamp and Q-switch. Analysis of the EPR spectra was carried out with the Bruker Xepr 2.1 software.

\section{References}

1. Satkoski, A. M., Beukes, N. J., Li, W., Beard, B. L. \& Johnson, C. M. A redox-stratified ocean 3.2 billion years ago. Earth Planet. Sci. Lett. 430, 43-53 (2015).

2. Yoon, H. S., Hackett, J. D., Ciniglia, C., Pinto, G. \& Bhattacharya, D. A Molecular Timeline for the Origin of Photosynthetic Eukaryotes. Mol. Biol. Evol. 21, 809-818 (2004).

3. Renger, G. \& Renger, T. Photosystem II: The machinery of photosynthetic water splitting. Photosynth. Res. 98, 53-80 (2008)

4. Jensen, P. E. et al. Structure, function and regulation of plant photosystem I. Biochim. Biophys. Acta 1767, 335-352 (2007)

5. Blankenship, R. E. Molecular Mechanisms of Photosynthesis. 2nd edn, (Wiley-Blackwell, 2014).

6. Caffarri, S., Tibiletti, T., Jennings, R. C. \& Santabarbara, S. A Comparison Between Plant Photosystem I and Photosystem II Architecture and Functioning. Curr. Protein Pept. Sci. 15, 296-331 (2014).

7. Vinyard, D. J., Ananyev, G. M. \& Dismukes, G. C. Photosystem II: The Reaction Center of Oxygenic Photosynthesis. Annu. Rev. Biochem. 82, 577-606 (2013).

8. Cardona, T., Sedoud, A., Cox, N. \& Rutherford, A. W. Charge separation in Photosystem II: A comparative and evolutionary overview. Biochim. Biophys. Acta 1817, 26-43 (2012).

9. Emerson, R., Chalmers, R. \& Cederstrand, C. Some factors influencing the long-wave limit of photosynthesis. Proc. Natl. Acad. Sci. USA 43, 133-143 (1957).

10. Blankenship, R. E. In Molecular Mechanisms of Photosynthesis 124-156 (Blackwell Science Ltd, 2008).

11. Miyashita, H. et al. Chlorophyll d as a major pigment. Nature 383, 402-402 (1996).

12. Miyashita, H. et al. Pigment composition of a novel oxygenic photosynthetic prokaryote containing chlorophyll d as the major chlorophyll. Plant Cell Physiol. 38, 274-281 (1997).

13. Chen, M., Quinnell, R. G. \& Larkum, A. W. D. The major light-harvesting pigment protein of Acaryochloris marina. FEBS Lett. 514, 149-152 (2002).

14. Chen, M. et al. The nature of the photosystem II reaction centre in the chlorophyll $d$-containing prokaryote, Acaryochloris marina. Photochem. Photobiol. Sci. 4, 1060-1064 (2005).

15. Loughlin, P., Lin, Y. \& Chen, M. Chlorophyll $d$ and Acaryochloris marina: current status. Photosynth. Res. 116, 277-293 (2013).

16. Tomo, T. et al. Identification of the special pair of photosystem II in a chlorophyll d-dominated cyanobacterium. Proc. Natl. Acad. Sci. USA 104, 7283-7288 (2007).

17. Hu, Q. et al. A photosystem I reaction center driven by chlorophyll d in oxygenic photosynthesis. Proc. Natl. Acad. Sci. USA 95 , 13319-13323 (1998).

18. Kuhl, M., Chen, M., Ralph, P. J., Schreiber, U. \& Larkum, A. W. D. Ecology: A niche for cyanobacteria containing chlorophyll $d$. Nature 433, 820-820 (2005).

19. Greenbaum, N. L. \& Mauzerall, D. Effect of irradiance level on distribution of chlorophylls between PS II and PS I as determined from optical cross-sections. Biochim. Biophys. Acta. 1057, 195-207 (1991).

20. Pettai, H., Oja, V., Freiberg, A. \& Laisk, A. Photosynthetic activity of far-red light in green plants. Biochim. Biophys. Acta 1708, 311-321 (2005)

21. Pettai, H., Oja, V., Freiberg, A. \& Laisk, A. The long-wavelength limit of plant photosynthesis. FEBS Lett. 579, 4017-4019 (2005).

22. Thapper, A., Mamedov, F., Mokvist, F., Hammarström, L. \& Styring, S. Defining the Far-Red Limit of Photosystem II in Spinach. Plant Cell 21, 2391-2401 (2009).

23. Hughes, J. L., Smith, P., Pace, R. \& Krausz, E. Charge separation in photosystem II core complexes induced by 690-730 nm excitation at 1.7 K. Biochim. Biophys. Acta 1757, 841-851 (2006).

24. Hughes, J. L. et al. Highly Efficient Spectral Hole-Burning in Oxygen-Evolving Photosystem II Preparations. J. Phys. Chem. B 108, 10428-10439 (2004).

25. Mokvist, F., Sjöholm, J., Mamedov, F. \& Styring, S. The Photochemistry in Photosystem II at 5 K Is Different in Visible and Far-Red Light. Biochemistry 53, 4228-4238 (2014).

26. Umena, Y., Kawakami, K., Shen, J.-R. \& Kamiya, N. Crystal structure of oxygen-evolving photosystem II at a resolution of 1.9 Å. Nature 473, 55-60 (2011).

27. Mieghem, F. J. E. V., Searle, G. F. W., Rutherford, A. W. \& Schaafsma, T. J. The influence of the double reduction of $Q_{A}$ on the fluorescence decay kinetics of Photosystem II. Biochim. Biophys. Acta. 1100, 198-206 (1992).

28. Mieghem, F. J. E. V., Nitschke, W., Mathis, P. \& Rutherford, A. W. The influence of the quinone-iron electron acceptor complex on the reaction centre photochemistry of Photosystem II. Biochim. Biophys. Acta. 977, 207-214 (1989).

29. Vass, I. \& Styring, S. Spectroscopic characterization of triplet forming states in photosystem II. Biochemistry 31, 5957-5963 (1992).

30. Klimov, V. V., Dolan, E., Shaw, E. R. \& Ke, B. Interaction between the intermediary electron acceptor (pheophytin) and a possible plastoquinone-iron complex in photosystem II reaction centers. Proc. Natl. Acad. Sci. USA 77, 7227-7231 (1980).

31. Rutherford, A. W. \& Zimmermann, J. L. A new EPR signal attributed to the primary plastosemiquinone acceptor in Photosystem II. Biochim. Biophys. Acta 767, 168-175 (1984).

32. Chen, G., Allahverdiyeva, Y., Aro, E.-M., Styring, S. \& Mamedov, F. Electron paramagnetic resonance study of the electron transfer reactions in photosystem II membrane preparations from Arabidopsis thaliana. Biochim. Biophys. Acta 1807, 205-215 (2011).

33. Danielsson, R., Albertsson, P.-Å., Mamedov, F. \& Styring, S. Quantification of photosystem I and II in different parts of the thylakoid membrane from spinach. Biochim. Biophys. Acta 1608, 53-61 (2004).

34. Babcock, G. T. \& Sauer, K. Electron paramagnetic resonance Signal II in spinach chloroplasts. I. Kinetic analysis for untreated chloroplasts. Biochim. Biophys. Acta 325, 483-503 (1973).

35. Mamedov, F., Sayre, R. T. \& Styring, S. Involvement of Histidine 190 on the D1 Protein in Electron/Proton Transfer Reactions on the Donor Side of Photosystem II. Biochemistry 37, 14245-14256 (1998).

36. Budil, D. E. \& Thurnauer, M. C. The chlorophyll triplet state as a probe of structure and function in photosynthesis. Biochim. Biophys. Acta 1057, 1-41 (1991).

37. Feikema, W. O., Gast, P., Klenina, I. B. \& Proskuryakov, I. I. EPR characterisation of the triplet state in photosystem II reaction centers with singly reduced primary acceptor QA. Biochim. Biophys. Acta 1709, 105-112 (2005).

38. van Mieghem, F. J. E., Satoh, K. \& Rutherford, A. W. A chlorophyll tilted $30^{\circ}$ relative to the membrane in the Photosystem II reaction centre. Biochim. Biophys. Acta 1058, 379-385 (1991). 
39. Vass, I. et al. Reversible and irreversible intermediates during photoinhibition of photosystem II: stable reduced $\mathrm{Q}_{\mathrm{A}}$ species promote chlorophyll triplet formation. Proc. Natl. Acad. Sci. USA 89, 1408-1412 (1992).

40. Lendzian, F., Bittl, R., Telfer, A. \& Lubitz, W. Hyperfine structure of the photoexcited triplet state ${ }^{3} \mathrm{P}_{680}$ in plant PS II reaction centres as determined by pulsed ENDOR spectroscopy. Biochim. Biophys. Acta 1605, 35-46 (2003).

41. Groot, M. L. et al. Temperature-dependent triplet and fluorescence quantum yields of the photosystem II reaction center described in a thermodynamic model. Biophys. J. 67, 318-330 (1994).

42. Rutherford, A. W. Orientation of EPR signals arising from components in Photosystem II membranes. Biochim. Biophys. Acta 807, 189-201 (1985).

43. Rutherford, A. W. \& Acker, S. Orientation of the primary donor in isolated photosystem II reaction centers studied by electron paramagnetic resonance. Biophys. J. 49, 101-102 (1986).

44. Reimers, J. R. et al. Challenges facing an understanding of the nature of low-energy excited states in photosynthesis. Biochim. Biophys. Acta 1857, 1627-1640 (2016).

45. Mori, T. \& Inoue, Y. Charge-transfer excitation: unconventional yet practical means for controlling stereoselectivity in assymetric photoreactions. Chem. Soc. Rev. 42, 8122-8133 (2013).

46. Noguchi, T., Tomo, T. \& Inoue, Y. Fourier Transform Infrared Study of the Cation Radical of P680 in the Photosystem II Reaction Center: Evidence for Charge Delocalization on the Chlorophyll Dimer. Biochemistry 37, 13614-13625 (1998).

47. Noguchi, T., Tomo, T. \& Kato, C. Triplet Formation on a Monomeric Chlorophyll in the Photosystem II Reaction Center As Studied by Time-Resolved Infrared Spectroscopy. Biochemistry 40, 2176-2185 (2001).

48. Raszewski, G., Saenger, W. \& Renger, T. Theory of Optical Spectra of Photosystem II Reaction Centers: Location of the Triplet State and the Identity of the Primary Electron Donor. Biophys. J. 88, 986-998 (2005).

49. Groot, M. L. et al. Initial electron donor and acceptor in isolated Photosystem II reaction centers identified with femtosecond midIR spectroscopy. Proc. Natl. Acad. Sci. USA 102, 13087-13092 (2005).

50. Romero, E., van Stokkum, I. H. M., Novoderezhkin, V. I., Dekker, J. P. \& van Grondelle, R. Two Different Charge Separation Pathways in Photosystem II. Biochemistry 49, 4300-4307 (2010).

51. Romero, E. et al. Mixed Exciton-Charge-Transfer States in Photosystem II: Stark Spectroscopy on Site-Directed Mutants. Biophys. J. 103, 185-194 (2012).

52. Romero, E., Novoderezhkin, V. I. \& van Grondelle, R. Quantum design of photosynthesis for bio-inspired solar-energy conversion. Nature 543, 355-365 (2017).

53. Novoderezhkin, V. I., Romero, E., Dekker, J. P. \& van Grondelle, R. Multiple Charge-Separation Pathways in Photosystem II: Modeling of Transient Absorption Kinetics. ChemPhysChem 12, 681-688 (2011).

54. Raszewski, G., Diner, B. A., Schlodder, E. \& Renger, T. Spectroscopic Properties of Reaction Center Pigments in Photosystem II Core Complexes: Revision of the Multimer Model. Biophys. J. 95, 105-119 (2008).

55. Holzwarth, A. R. et al. Kinetics and mechanism of electron transfer in intact photosystem II and in the isolated reaction center: Pheophytin is the primary electron acceptor. Proc. Natl. Acad. Sci. USA 103, 6895-6900 (2006).

56. Berthold, D. A., Babcock, G. T. \& Yocum, C. F. A highly resolved, oxygen-evolving photosystem II preparation from spinach thylakoid membranes: EPR and electron-transport properties. FEBS Lett. 134, 231-234 (1981).

57. Völker, M., Ono, T., Inoue, Y. \& Renger, G. Effect of trypsin on PS-II particles. Correlation between Hill-activity, Mn-abundance and peptide pattern. Biochim. Biophys. Acta 806, 25-34 (1985).

58. Havelius, K. G. V., Su, J.-H., Feyziyev, Y., Mamedov, F. \& Styring, S. Spectral Resolution of the Split EPR Signals Induced by Illumination at $5 \mathrm{~K}$ from the $\mathrm{S}_{1}, \mathrm{~S}_{3}$, and $\mathrm{S}_{0}$ States in Photosystem II. Biochemistry 45, 9279-9290 (2006).

59. Ahmadova, N., Ho, F. M., Styring, S. \& Mamedov, F. Tyrosine D oxidation and redox equilibrium in photosystem II. Biochim. Biophys. Acta 1858, 407-417 (2017).

60. Mamedov, F., Stefansson, H., Albertsson, P.-Å. \& Styring, S. Photosystem II in Different Parts of the Thylakoid Membrane: A Functional Comparison between Different Domains. Biochemistry 39, 10478-10486 (2000).

\section{Acknowledgements}

This work was supported by the Swedish Research Council (VR) and the Swedish Energy agency.

\section{Author Contributions}

S.S. and F.M. conceived the experiments, A.P., J.J. and N.A. conducted the experiments, A.P. and J.J. analysed the results. A.P., S.S., and F.M. wrote the manuscript.

\section{Additional Information}

Competing Interests: The authors declare no competing interests.

Publisher's note: Springer Nature remains neutral with regard to jurisdictional claims in published maps and institutional affiliations.

Open Access This article is licensed under a Creative Commons Attribution 4.0 International License, which permits use, sharing, adaptation, distribution and reproduction in any medium or format, as long as you give appropriate credit to the original author(s) and the source, provide a link to the Creative Commons license, and indicate if changes were made. The images or other third party material in this article are included in the article's Creative Commons license, unless indicated otherwise in a credit line to the material. If material is not included in the article's Creative Commons license and your intended use is not permitted by statutory regulation or exceeds the permitted use, you will need to obtain permission directly from the copyright holder. To view a copy of this license, visit http://creativecommons.org/licenses/by/4.0/.

(C) The Author(s) 2018 